\title{
Pedro Miguel Omar Svriz Wucherer, Resistencia y negociación. Milicias guaraníes, jesuitas y cambios socioeconómicos en la frontera del imperio global hispánico: ss. XVII-XVIII, Prohistoria, Rosario, 2019
}

Aldana Agrano*

Cuadernos de Historia. Serie economía y sociedad, N²6/27, 2021, pp. 417 a 421. RECIBIDO: 09/04/2021. EVALUADO: 01/06/2021. ACEPTADO: 15/06/2021.

Las misiones jesuíticas del Paraguay constituyen un tópico privilegiado del estudio de la historia colonial americana. Desde los inicios mismos de su conformación en el siglo XVII, tanto defensores como detractores de la Compañía de Jesús han escrito y difundido alrededor del globo todo tipo de relatos sobre ellas. La historiografía de los siglos XIX y XX volvió una y otra vez sobre esas historias - que se convirtieron en fuentes esenciales para la investigación sobre dichas misiones - impulsadas por preguntas estimulantes desde las más diversas miradas, pero siempre como un caso emblemático de la interacción entre colonizados y colonizadores. En esta oportunidad, Pedro Miguel Omar Svriz Wucherer estudia el accionar de las milicias guaraníes en relación con la Compañía de Jesús y las autoridades de la Monarquía hispánica entre los siglos XVII y XVIII.

El autor de Resistencia y Negociación. Milicias guaranies, jesuitas y cambios socioeconómicos en la frontera del imperio global hispánico, ss. XVII-XVIII cursó sus estudios de grado en Historia en la Universidad Nacional del Nordeste (Corrientes, Argentina) y de posgrado en la Universidad Pablo de Olavide (Sevilla, España). Este libro es producto de su tesis doctoral dirigida por Bartolomé Yun Casalilla, quien en el

* Universidad Nacional de Rosario. E mail: aldana.p.agrano@gmail.com 
\begin{tabular}{r|r} 
A. Agrano & 26/27: pp.417-421 \\
Cuadernos de Historia. Serie economía y sociedad &
\end{tabular}

prólogo destaca las preguntas generales que guiaron la investigación sobre las formas de gobierno de los imperios ibéricos y cómo, a partir de allí, Svriz pudo analizar un caso local como parte de un proceso mayor con alcance global.

En la introducción, Svriz se propone inscribir su objeto de estudio en una historia global que explique el rol de las milicias guaraníes como defensa de una región fronteriza atravesada por conflictos interimperiales a lo largo de dos siglos de dominación colonial hispana y portuguesa en América del Sur. Para ello, se pregunta por la política económica y militar que desarrollaron los imperios ibéricos en la protección de las fronteras del Paraguay y Río de la Plata. Resalta la importancia de la negociación con los agentes locales (autoridades, jesuitas, pueblos guaraníes) para sostener el sistema militar defensivo. Caracteriza estas relaciones como un pacto conflictivo entre dichos agentes, en el cual se disputaban diversos intereses pero que, al mismo tiempo, garantizaba la protección de la frontera. A su vez, plantea la posibilidad de conectar estos ejes con transformaciones de largo aliento que provocaron cambios socioculturales profundos en los habitantes de la región.

Metodológicamente, sugiere una mirada amplia y global sobre las milicias guaraníes siguiendo un juego de escalas que recupere la multiplicidad de relaciones en diferentes puntos de los imperios. Se apoya en los planteos teóricos de Gruzinski sobre las historias conectadas y en los enfoques de los estudios subalternos para mirar a los pueblos guaraníes como poblaciones subordinadas que, lejos de aceptar pasivamente esa condición, obtuvieron algunos beneficios a través de su rol como defensores de la frontera imperial. Destaca también los aportes de la antropología histórica y los estudios interétnicos de fronteras: retoma principalmente a Boccara y Giudicelli, de quienes recupera los análisis sobre las fronteras indígenas - alejándose de la mirada eurocéntrica - y el rol de los nativos en la configuración de esos espacios. En esa línea, se vale especialmente de los trabajos del antropólogo Guillermo Wilde, quien pondera la agencia indígena como un elemento clave para pensar los vínculos políticos y los diversos intereses que se ponían en juego en la frontera hispano-lusitana del Paraguay y Río de la Plata.

El cuerpo del libro se divide en cinco capítulos y un epílogo. De manera progresiva, el autor se aproxima a su objeto de estudio haciendo un recorrido en forma de reloj de arena: comienza con un análisis general en el primer capítulo sobre las realidades 
de los pueblos guaraníes previo a la llegada de los conquistadores, para luego adentrarse en el proceso de conquista, colonización y evangelización europea en la cuenca rioplatense. En el capítulo dos, se concentra en la tradición guerrera de los pueblos guaraníes y de qué manera fue encausada por los padres jesuitas para consolidar el establecimiento de las reducciones y la protección de la frontera interimperial. En el tercer capítulo, el foco de observación se detiene puntualmente sobre las intervenciones de las milicias guaraníes de un pueblo particular y sus relaciones con los padres jesuitas y las autoridades locales. Ya en los capítulos cuatro y cinco, Svriz vuelve a ampliar la lente en tiempo y espacio. Primeramente, recorre el siglo XVII analizando los cambios armamentísticos y tecnológicos que posibilitaron la consolidación de las milicias guaraníes. Luego, abre su estudio a los cambios en las estructuras económicas y sociales producidas a lo largo de dos siglos de presencia jesuita en la región analizando las modificaciones en las técnicas de producción agrícola, pautas de consumo, patrones de asentamiento, noción del uso del tiempo y prácticas bélicas; y cómo éstas posibilitaron la inserción de los guaraníes en el sistema imperial. Hacia el final, Svriz desarrolla brevemente en el epílogo el impacto de las reformas borbónicas en el Paraguay y el Río de la Plata desde los inicios del siglo XVIII y de qué modo las milicias guaraníes fueron relegadas a un segundo plano a la hora de organizar la defensa fronteriza.

Este libro conjuga varios registros de análisis. Desde la trama política, la negociación es uno de los ejes principales que involucra a todos los actores del proceso histórico abordado. El autor estudia las disputas de intereses entre nativos, jesuitas y autoridades monárquicas, tanto americanas como peninsulares. Enfatiza en la consolidación del mencionado pacto conflictivo que garantizó la convivencia en la región rioplatense. Por un lado, sugiere que la Monarquía cedió la custodia de la frontera a las milicias guaraníes impulsadas por los padres jesuitas y comandadas por los gobernadores locales; generando una descentralización del uso de la violencia en el terreno al dejar en manos de particulares americanos la protección de los territorios ultramarinos. Estos agentes locales fortalecieron su poder enfrentando tanto a portugueses del Brasil que avanzaban desde el este como a indios no reducidos que asolaban las ciudades hispanas. Por el otro, plantea que la conformación de las milicias guaraníes reportaba beneficios para los líderes reducidos que se destacaban 
\begin{tabular}{r|r} 
A. Agrano & 26/27: pp.417-421 \\
Cuadernos de Historia. Serie economía y sociedad &
\end{tabular}

en los enfrentamientos y a su vez maximizaba los escasos recursos de la Monarquía para defender sus fronteras en la región.

No obstante, Svriz también estudia los vaivenes de ese pacto, según prosperaban, o no, las alianzas en cada caso. Las tensiones intrínsecas generaban conflictos y resistencias coyunturales que iban modificando los acuerdos a través del tiempo. En ese sentido, el autor muestra la heterogeneidad de los pueblos nativos que habitaban las fronteras, sus estrategias e interacciones, con el objetivo de desarmar la dicotomía de indios amigos/enemigos como categorías estáticas y entenderlas en función de cada contexto particular.

Sus propuestas se construyen a partir de un amplio abanico de fuentes escritas editadas e inéditas que van desde disposiciones oficiales - como reales cédulas y autos de gobernadores - hasta crónicas y cartas jesuitas que organizaban la administración de las misiones y la participación de las milicias guaraníes. Los análisis de casos particulares fueron elaborados a partir de visitas de gobernadores del Paraguay a las reducciones, que contienen tanto datos de la población y de sus recursos económicos como reclamos de sus pobladores. A su vez, para estudiar las formas de resistencia directa el autor se basa en testimonios tomados en el marco de un proceso judicial iniciado como consecuencia de una rebelión de nativos.

En el ámbito socioeconómico, es destacable el abordaje de fuentes cualitativas que contienen diferentes descripciones producidas por jesuitas para considerar los usos y costumbres de la utilización de armas, las tareas agrícolas y la movilización de los recursos necesarios para los enfrentamientos armados. Svriz analiza los vínculos comerciales de la Compañía de Jesús como un medio fundamental para la venta de los productos de las reducciones a cambio de armas y hierro para su fabricación. A los circuitos entre los colegios jesuitas asentados en las ciudades del Virreinato del Perú, suma transacciones con portugueses que llegaban desde el este, matizando la imagen de una frontera interimperial únicamente atravesada por conflictos bélicos. Por otra parte, para explicar las transformaciones sufridas por los pueblos nativos a lo largo de dos siglos, utiliza la categoría de revolución neolítica, presentada como un proceso inducido y acelerado por los padres jesuitas que produjo la sedentarización de los nativos que lograron reducir e insertó a esas poblaciones en un proceso de 
globalización de la tecnología bélica a escala imperial mediante la conformación de milicias basadas en los formatos europeos.

Por todo, este libro abre camino para nuevos debates sobre los estudios de las misiones jesuíticas del Paraguay a partir de novedosas categorías. La posibilidad de analizar las transformaciones estructurales provocadas por la conquista y colonización europea en la región a través de la mencionada revolución neolítica motiva a reflexionar sobre las múltiples violencias que supusieron la imposición de un modo completamente diferente de organizar la reproducción de la vida material por parte de los europeos sobre la población nativa que, lejos de surgir de un proceso endógeno del desarrollo propio de las sociedades americanas, fueron provocadas con el objetivo de facilitar la sujeción y asemejar los nuevos dominios hispánicos a la realidad europea y cristiana. Asimismo, la noción de pacto conflictivo que pondera las instancias de negociación forjadas al calor de dicho proceso, habilita la pregunta por el peso que se le asigne a la relación asimétrica de dominación colonial que a fin de cuentas condicionaba las estrategias de supervivencia desarrolladas por los pueblos guaraníes.

La incorporación de los territorios ultramarinos al conjunto político de la Monarquía castellana y de la cristiandad católica implicó la conformación de una multiplicidad de centros de poder mediante la consolidación de elites locales que gobernaban en nombre de un rey distante, valiéndose de amplios márgenes de autonomía para resolver los conflictos cotidianos en sus respectivas jurisdicciones. En suma, la conformación de milicias guaraníes para la defensa de la frontera interimperial puede ser abordada como parte de las agencias localizadas de gobierno, tanto de las autoridades monárquicas como del clero regular, que posteriormente fueron convalidadas por la Corona para asegurar la conservación de sus dominios en el extremo sur del imperio, hasta la reconfiguración de la política fronteriza impulsada por los borbones en el transcurso del siglo XVIII. 